\title{
Experimental Investigation and Numerical Prediction of the Effects of Cutting Tool Geometry During Turning of AISI 316L Steel
}

\author{
Amor Benmeddour ${ }^{1 *}$ \\ ${ }^{1}$ Department of Mechanical Engineering, Faculty of Sciences Technology, University of Brothers Mentouri, 25000 Constantine, \\ 1 Route de Ain El Bey, Algeria \\ * Corresponding author, e-mail: omar.meca.2017@gmail.com
}

Received: 13 July 2020, Accepted: 08 May 2021, Published online: 06 September 2021

\begin{abstract}
In this work, a numerical and an experimental study aimed to gain a better understanding of the impact of tool geometry such as (rake angle and cutting edge radius) on the temperature distribution and residual stresses in machining surface of AISI 316L stainless steel have been presented. To evaluate the experimental results, various experimental equipment was used, such as a conventional lathe to carry out the machining operations, the cutting force was measured using a Kistler dynamometer and X-ray diffraction technique was employed for determination of the residual stresses distribution on the machined surfaces. In addition, A thermo-mechanically coupled finite element (FE) analysis for cutting process is developed through ABAQUS code to predict the temperature distribution and residual stresses using an Arbitrary Lagrangian-Eulerian (ALE) approach. An inverse identification method has been used to determine the adequate Johnson-Cook (JC) material model parameters to obtain a good correlation between the cutting force measurements and numerical one. The FE model was then validated by comparison of the numerical results of residual stresses with experimental measurements for different tool geometries, which revealed a reasonable agreement.
\end{abstract}

\section{Keywords}

metal cutting, FEM, JC material parameters, tool geometry, cutting force, temperature distribution, residual stress

\section{Introduction}

In the machining process, the quality of the produced parts are strongly affected by the state of the induced residual stresses, which are influenced by numerous parameters such as depth of cut, cutting speed, feed rate and the geometrical features of the tool. Moreover, a severe mechanical load and a high temperature, in the localized tool-workpiece contact zone, in the machining process weakens tool resistance and causes accelerated tool wear and chipping of the cutting edge. High-temperature gradients lead to residual stresses on the finish surface of the product which results in a reduction of product life and low quality of machined surfaces. Therefore, many studies have been done to optimize cutting parameters and increase the life of cutting tools to meet industry requirements [1-4]. Different experimental studies techniques have been used in the past for measuring cutting temperature in the machining process $[5,7]$. Unfortunately, experimental measurement is difficult to practice because during the cutting of metal a complex contact phenomena occur between the workpiece and the cutting tools, and because of the limited accessibility during the cutting process [8]. In the last few years, the numerical models based on a FEM have been widely employed by many researchers for simulations of metal cutting process because of their capability to furnish predictions for several parameters of the process such as cutting forces, temperatures and residual stress in the workpiece and chip morphology which can serve out to optimize metal cutting processes and improve the design of the cutting tool, increase the productivity and minimize the machining cost [4, 9-17]. because of the important role that the cutting tool geometry plays on the performance of machining operations, the influence of tool geometry on machinability has acquired considerable attention in the scientific literature. Yen et al. [11] studied the effect of tool geometry on machining process using a finite element model to optimize the design of tool edges. The effects of the tool geometry on residual stresses induced by machining process have been analysed by many researchers, for 
example, M'Saoubi et al. [13], Miguilez et al. [14], and it has been demonstrated by Outeiro [15] that the level of residual tensile stresses increases with the feed rate, cutting angle and the radius of the cutting edge. MuñozSánchez et al. [18] used a finite element method to analyze the tool wear influence on residual stress during the machining operations. The Characterization of AISI 316L steel has been the subject of great interest in the literature due to their excellent mechanical properties. In the absence of a dedicated testing methods to assess the flow of residual stress in the workpiece the researcher [19] reported various sets of johnson cook material parameters used in the literature and concluded that the values of these parameters influence the predicted residual stresses. Other authors [20] recommend the use of inverse identification method to determine the JC material model parameters set by examining the chip morphology and the cutting force, a similar approach was used in this study. The numerical simulations with finite element model (FEM) and cutting experiments are performed. Firstly, to identify the best JC material parameters to obtain a good correlation between measured cutting force and predicted one and the validation of the residual stress profile obtained numerically. Then, the second purpose is to investigate and understand the influence of tool rake angle and tool edge radius on the temperature distribution and the generation of residual stress in machining.

\section{Numerical model}

In this paper, an ALE plane strain model has been developed using Abaqus / Explicit software. Eulerian, Lagrangian and Arbitrary Lagrangian-Eulerian (ALE) techniques have been employed for the simulation of cutting process. The ALE model is a combination of Lagrangian and Eulerian formulations. In fact, the mesh can be fixed in the Eulerian regions and can follow the movement of the material in the Lagrangian regions. In addition, the mesh can move arbitrarily in order to reduce the deformation of the elements and to produce the geometry of the chip without using damage criteria. However, an initial shape of the chip must be predefined in the design of the model in order to avoid distortion of the mesh, occurring in particular at the start of the cutting simulation. In the present work, an ALE model using a Lagrangian trend developed by Muñoz-Sánchez et al. [18] was used. Fig. 1 presents the basic geometry and dimensions of the adopted model. The undeformed mesh geometry, which presents main characteristics of the model is illustrated in Fig. 2. The workpiece

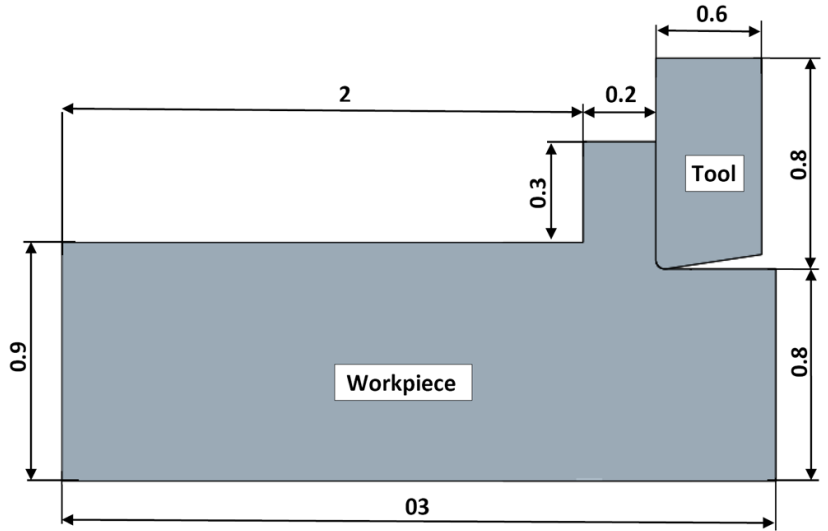

Fig. 1 The basic geometry and dimensions of the FE model

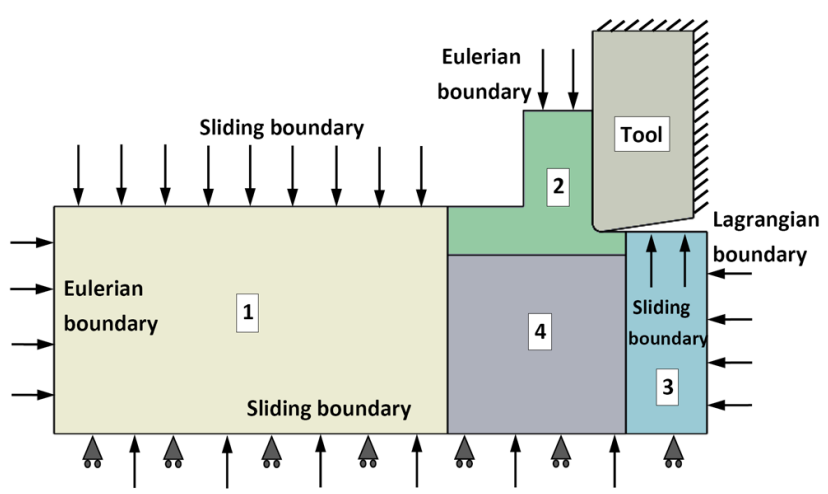

Fig. 2 Implementation of the boundary conditions and contour's type

is divided in several regions. Regions 1 to 3 combine sliding, Lagrangian and Eulerian boundaries, under these conditions the material can flow tangentially to the contour and must not cross this contour. The Eulerian boundaries in region 2 and at the entrance to region 1 present the initial chip geometry in order to avoid the excessive deformation of the mesh during the simulation. Region 4 is a Eulerian region in which the mesh is fixed, In this way the materials can flow across this region. The tool is fixed and the workpiece moves with an imposed cutting velocity. However, unlike the previous paper [10], the formation of chips is assumed to be of the continuous type.

A coupled thermomechanical analysis was performed using a mesh composed of elements type CPE4RT for both cutting tool and workpiece mesh zone. The CPE4RT is a plain strain 4-node quadrilateral elements, and thermal coupled elements with reduced integration with hourglass control adapted for 2D numerical analysis. The number of elements varies depending on the geometry of the tool used in the simulation.

The main benefit of the ALE method was the small level of distortion obtained in the area surrounding the cutting tool tip, at the same time the technique does not require 
the use of chip separation criteria.

This study focused on the influence of the tool geometry. The basic geometry (zero rake angle, cutting edge radius $\mathrm{R}=0.02 \mathrm{~mm}$ ) was modified to analyse various rake angle of the tool (from 0 to $10^{\circ}$ ) and different cutting edge radius (from 0.02 to $0.06 \mathrm{~mm}$ ). The tool was fixed in all directions. The workpiece moves in the $\mathrm{x}$ direction at the cutting speed of $100 \mathrm{~m} / \mathrm{min}$, the cutting depth was set at $0.2 \mathrm{~mm}$, the clearance angle is $7^{\circ}$ and the initial temperature was assumed to be $20^{\circ} \mathrm{C}$. The physical properties of the workpiece (AISI 316L steel) and the cutting tool materials (cemented carbide) were obtained from [21] and are given in Table 1.

\subsection{Frictional model}

The interaction between the carbide tool and the AISI 316L steel chip can be represented by the simple Coulomb friction law that was employed in several scientific paper [22, 23]. In this study a coefficient of friction equal to 0.3 was assumed which closely reproduces the residual stress measured in the experimental tests.

\subsection{Heat transfer generation}

The heat generated during the cutting process is due to friction and plastic deformation of the material at the tool/chip and the tool/workpiece interfaces. The heat conduction and convective heat transfer from a free surface of the workpiece and chip to the environment are taken into account. A convective heat transfer coefficient of $20 \mathrm{~W} / \mathrm{m}^{2} . \mathrm{k}$ is used and radiation has been neglected.

\subsection{Johnson-Cook constitutive model}

The Johnson-Cook plasticity model for AISI 316L steel was adopted. The model is particularly useful for materials subject to large strain, high strain rates and high temperatures [24]. The flow stress of the material can be expressed by:

Table 1 Physical Properties of workpiece and cutting tool materials [21]

\begin{tabular}{lcc}
\hline Properties & AISI 316L steel & Cemented carbide \\
\hline $\begin{array}{l}\text { Density }\left(\rho, \mathrm{Kg} / \mathrm{m}^{3}\right) \\
\text { Young's modulus } \\
(\mathrm{E}, \mathrm{GPa})\end{array}$ & 8000 & 14900 \\
$\begin{array}{l}\text { Poisson Ratio }(v) \\
\text { Specific Heat }\end{array}$ & 193 & 615 \\
$(\mathrm{Cp}, \mathrm{J} / \mathrm{Kg} \mathrm{K})$ & 500 & 0.22 \\
$\begin{array}{l}\text { Thermal conductivity } \\
(\mathrm{k}, \mathrm{W} / \mathrm{m} \mathrm{K})\end{array}$ & 16.2 at $100{ }^{\circ} \mathrm{C}$ & 138 \\
$\begin{array}{l}\text { Melting temperature }\left({ }^{\circ} \mathrm{C}\right) \\
\text { Thermal expansion }\end{array}$ & 21.4 at $500{ }^{\circ} \mathrm{C}$ & 79 \\
coefficient $\left(\alpha, \mathrm{K}^{-1}\right)$ & 1385 & - \\
\hline
\end{tabular}

$\sigma_{e}=\left[A+B\left(\varepsilon_{e}^{p}\right)^{n}\right]\left[1+C \ln \left(\frac{\dot{\varepsilon}_{e}^{p}}{\dot{\varepsilon}_{0}}\right)\right]\left[1-\left(\frac{T-T_{a}}{T_{m}-T_{a}}\right)^{m}\right]$,

where $\varepsilon_{e}^{p}$ is the equivalent plastic strain, $\dot{\varepsilon}_{e}^{p}$ is the equivalent plastic strain rate and $\dot{\varepsilon}_{0}$ is the reference equivalent strain rate, $T, T_{a}$ and $T_{m}$ are the actual, ambient and melting temperature, respectively. $A$ is the elastic limit, $B$ and $n$ represent the effects of strain hardening, $C$ is the strain rate sensitivity constant and $m$ is thermal softening coefficient.

\section{Experimental tests and model validation}

In this study, several orthogonal cutting tests were performed out on a conventional lathe equipped with the following parameters: cutting speed $\mathrm{V}=100 \mathrm{~m} / \mathrm{min}$, feed rate $\mathrm{f}=0.1 \mathrm{~mm} / \mathrm{rev}$. Different tool geometries were used with: clearance angle of $7^{\circ}$, cutting edge radius $\mathrm{R}=0.02$ $\mathrm{mm}$, and various tool rake angle of $0^{\circ}, 5^{\circ}$ and $10^{\circ}$. To measure the cutting force generated during machining, a piezoelectric dynamometer type Kistler 9257B was used. The experimental configuration for measuring the forces during orthogonal cutting is illustrated in Fig. 3.

\subsection{Determination of material parameters}

Concerning the determination of the johnson-cook material parameters of the workpiece, an inverse method similar to that developed by [25] has been used in the present work, the JC model is used with a different set of material constants for AISI 316L steel obtained from the literature as starting values, see Table 2 . The appropriate value is then obtained after several simulation tests, LevenbergMarquardt optimisation algorithm was employed to determine the best material parameters set by comparing the

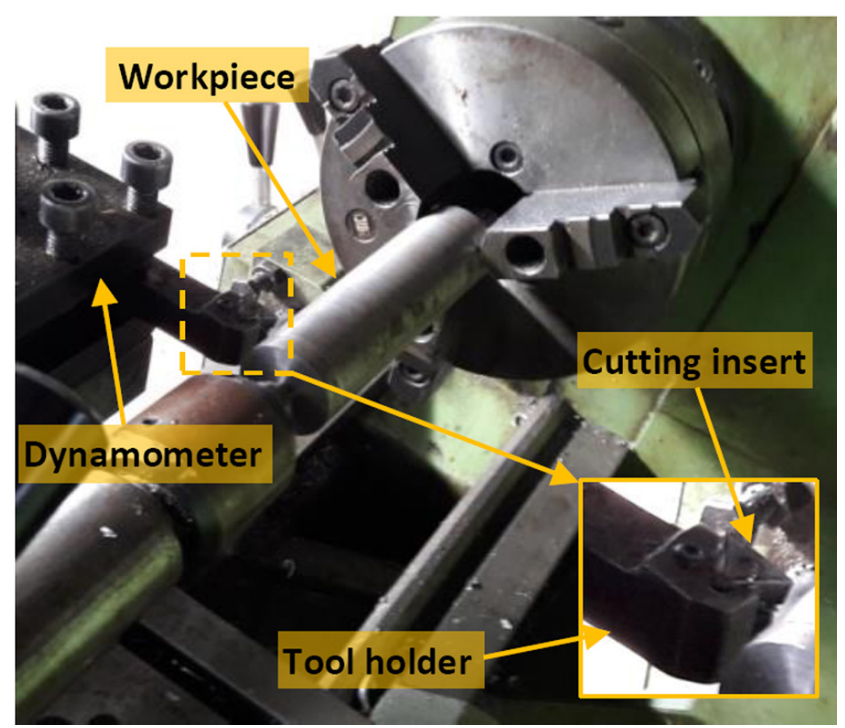

Fig. 3 The machining experimental setup 
Table 2 Johnson cook parameters for AISI 316L steel

\begin{tabular}{lcccccc}
\hline & $\begin{array}{c}A \\
{[\mathrm{MPa}]}\end{array}$ & $\begin{array}{c}B \\
{[\mathrm{MPa}]}\end{array}$ & $C$ & $n$ & $m$ & $\dot{\varepsilon}_{0}$ \\
\hline $\begin{array}{l}\text { Chandrasekaran et } \\
\text { al. [19] }\end{array}$ & 305 & 1161 & 0.010 & 0.610 & 0.517 & 1 \\
$\begin{array}{l}\text { Miguélez et al. [14] } \\
\text { Tounsi et al. [20] }\end{array}$ & 400 & 750 & 0.040 & 0.500 & 0.500 & 1 \\
Present work & 514 & 514 & 0.042 & 0.508 & 0.533 & $10^{-3}$ \\
& 412 & 761 & 0.038 & 0.510 & 0.520 & 1 \\
\hline
\end{tabular}

evolution of the cutting forces obtained experimentally by the author. These parameters of Jonhson-Cook law, were chosen so as to obtain a good correlation between the cutting force measurements carried out in the present study and numerical one. Table 2 gathers the selected set of parameters values for workpiece material, used in the simulation as materials input data. The proposed model with the adequate set of JC parameters that fits the values of the cutting forces obtained experimentally was then validated by comparison with the measured residual stresses after orthogonal turning tests.

Various simulations have been performed with the JC parameters found by other researchers $[14,19,20]$ and the proposed model are shown in Table 2 to predict the cutting force of the metal. The results of the measured and predicted cutting force are presented in Fig. 4, showing a good estimate of the cutting force.

\subsection{Residual stress measurements and model validation}

To verify the accuracy of the present numerical study, the residual stress field obtained by numerical calculation in the cutting direction $\left(\sigma_{11}\right)$ was compared with the experimental measurements under similar cutting conditions. The residual stress distribution at the machined surface of the AISI 316L steel workpiece was measured using the X-ray diffraction technique by the $\sin ^{2} \psi$ method [26], which was performed by Bruker AXS D8 Discover XRD machine. The parameters used in the X-ray analysis are shown in Table 3. To obtain the in-depth residual stress profiles, consecutive layers of the material have been removed with electropolishing.

The observation of Fig. 5 shows that the profile of predicted residual stress have the same trend compared with the

Table 3 X-ray diffraction parameter for residual stress measurement

\begin{tabular}{lc}
\hline Parameter & Condition \\
\hline Voltage and current & $25 \mathrm{kV}, 5 \mathrm{~mA}$ \\
Spot diameter $(\mathrm{mm})$ & 3 \\
X-ray elastic constants $\left(\mathrm{MPa}^{-1}\right)$ & $(1 / 2) \mathrm{S}_{2}=9.34 \mathrm{E}-6$ \\
Bragg angle $\left(^{\circ}\right)$ & $\mathrm{S}_{1}=-3.46 \mathrm{E}-6$ \\
\hline
\end{tabular}

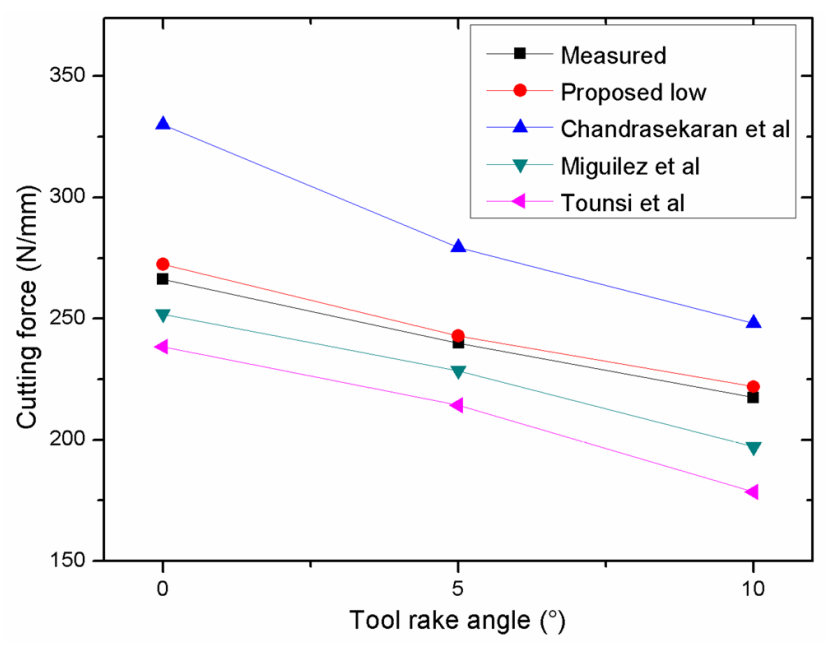

Fig. 4 Cutting forces measured and simulated

one measured by experience, it is clear that this curves indicate a state of tensile stresses at the surface machined, and as the depth increases. The magnitude of the tensile residual stress decrease quickly and result in a compression state, and finally with increasing depth, the amplitude of the residual stress decrease progressively to become null. It should also be noted that similar residual stress profiles have been found by the author in a previous work [10] and also by other researchers [14, 15, 21] for turning AISI 316 stainless steels.

In Fig. 5, the maximum tensile stress $\sigma_{11}$ predicted by simulation occurs on the surface of the workpiece and reaches the value of $654 \mathrm{MPa}$ which is very close to that measured with an error of $8 \%$. The thickness of tensile stress layer is about $0.15 \mathrm{~mm}$. Concerning the compressive residual stress is attains its maximum value of $-67 \mathrm{MPpa}$ at a depth of $0.26 \mathrm{~mm}$. Comparing this result with measured one, the error does not exceed $14 \%$.

The current FE model accurately predicted the residual stress profiles and trends one. Moreover the maximum

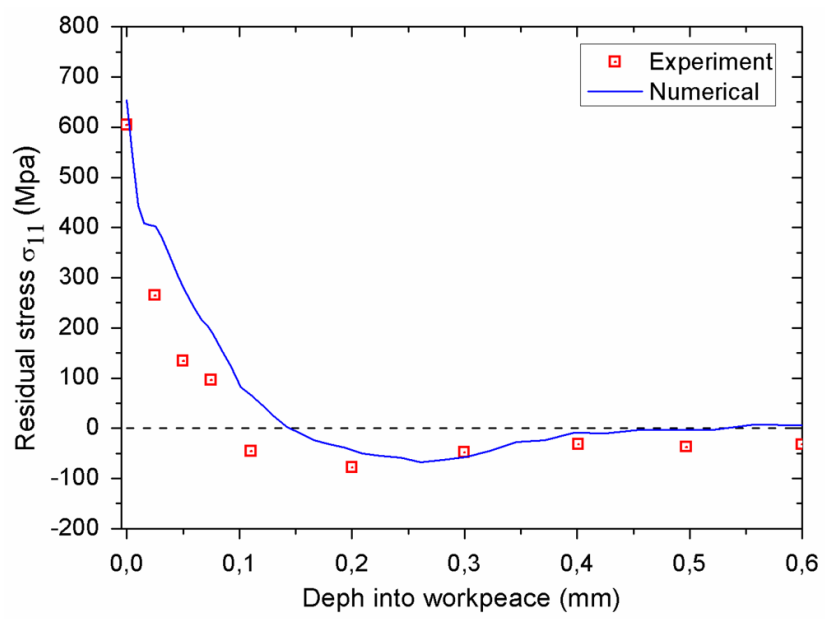

Fig. 5 Numerical and experimental residual stress profiles 
stress predicted par simulation was very close to the experimental measurements with an error less than $14 \%$ in all cases. consequently, the proposed FE model with the selected JC parameters values show its satisfactory capability to predict the residual stress distribution generated by machining operation.

\section{Numerical results and discussion}

In Section 4, a set of simulations was carried out to know the influence rake angle and the radius of the tool edge on the temperature distribution and the tensile residual stress in the machined workpiece. Then, the tensile residual stress at the surface were compared with those measured after turning.

\subsection{Influence of rake angle on temperature}

The problem of cutting temperature is an important parameter for the study of elevated speed machining, which greatly influences tool wear, tool service life, surface quality, machining efficiency and accuracy machined parts. To investigate the effect of tool rake angles, several simulations were carried out for various rake angles of $0^{\circ}, 5^{\circ}$ and $10^{\circ}$. Fig. 6 presents the distribution of the temperature for the chip and the tool during the machining process for different tool rake angles. The results reveal a high temperature region in the chip-tool interface, as the tool rake angle increase from $0^{\circ}$ to $10^{\circ}$, the maximum cutting temperature decreases from $632{ }^{\circ} \mathrm{C}$ to $514{ }^{\circ} \mathrm{C}$. This result is probably caused by the local heating induced by the friction between the contact surfaces of the tool and the chip, in fact an increase of the rake angle decrease the surface of contact between the chip and tool and consequently generates a lower friction between the removed material and cutting tool, this will also increase the cutting temperature.

\subsection{Influence of rake angle on residual stress}

The tensile residual stresses $\left(\sigma_{11}\right)$ variation versus the depth of the workpiece for various tool rake angles are shown in Fig. 7. It has been noted that tensile residual stresses can result from the competition between mechanical and thermal effects [14]. We can see that the magnitude of the tensile residual stress is reduced as the tool rake angle increases. We can see that the magnitude of the tensile residual stress is reduced as the tool rake angle increases. The maximum tensile residual stress was decreased from $654 \mathrm{MPa}$ to $494 \mathrm{MPa}$ (about $24 \%$ decrease) when the rake angles was increased from $0^{\circ}$ to $10^{\circ}$, showing that the thermal expansion effect is dominant, although the tool rake angle has a slight influence on the magnitude of compressive stresses (about $13 \%$ decrease). It should also be noted that the thickness of the tensile layer has not been changed with the increase in the cutting angle. a)

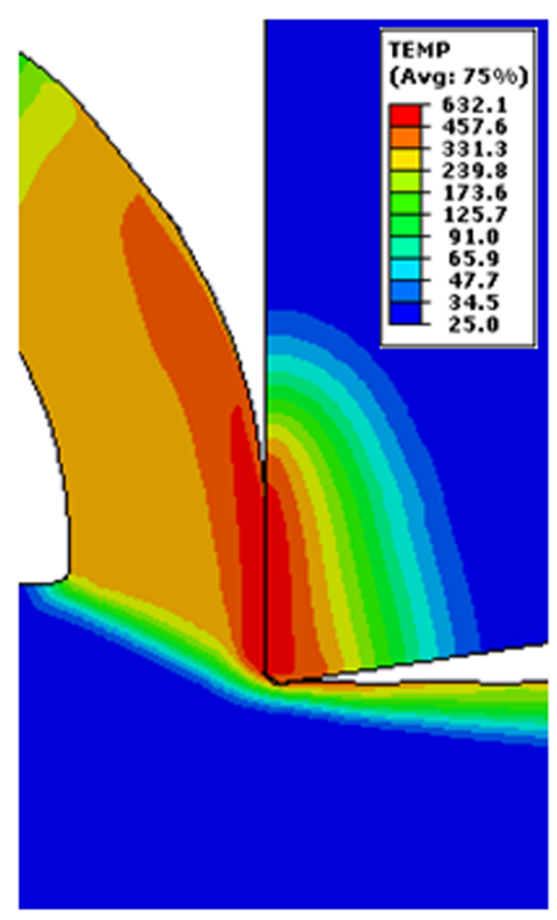

b)

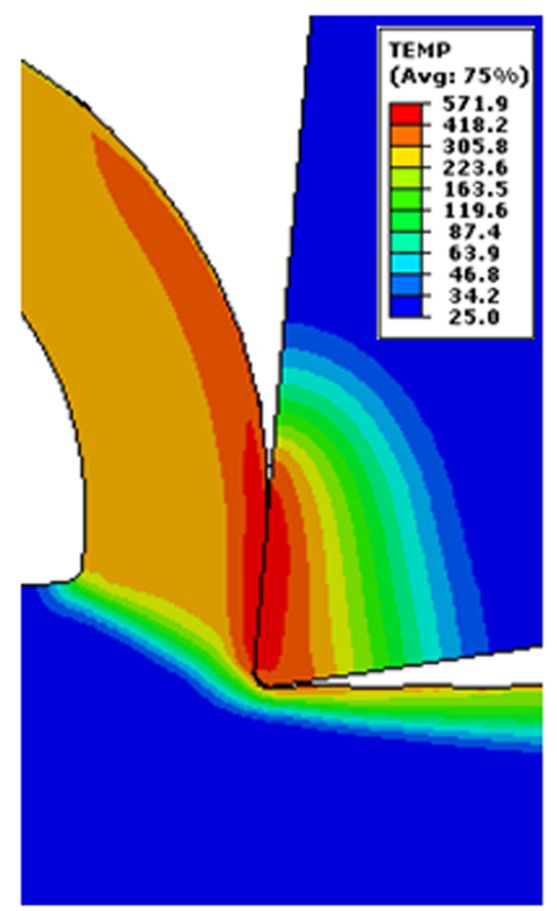

c)

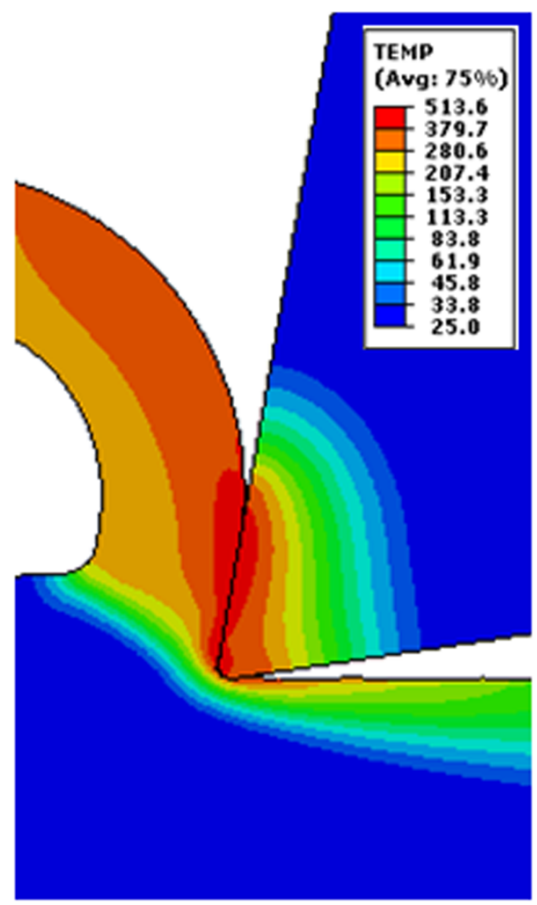

Fig. 6 The temperature distribution $\left(\mathrm{C}^{\circ}\right)$ at different rake angles: a) $\gamma=0^{\circ}$, b) $\gamma=5^{\circ}$, c) $\gamma=10^{\circ}$ 


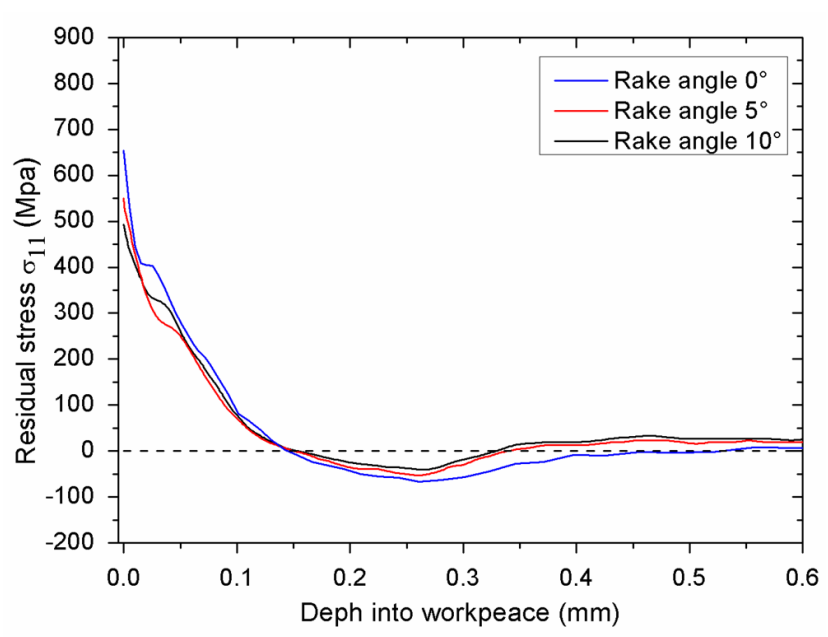

Fig. 7 Tensile residual stresses for various tool rake angles

The comparison of experimental results and numerical one of the surface tensile residual stresses are also presented in Fig. 8. It is clear that the predicted values are close to the measured experimental values where the error varies in 4 to $8 \%$.

\subsection{Influence of tool edge radius on temperature}

Fig. 9 presents the temperature distribution during cutting at different tool edge radius. The results show the high temperature region at the tool-chip interface; as the edge radius increase, the maximum temperature region on the interface extends toward the cutting edge, around the tip of tool. It can be clearly seen, that increasing the tool cutting edge radius induces an increasing of the maximum temperature, when the tool edge radius change from 0.02 to 0.06 , the maximum temperature at the tool-chip interface also increase from 632 to $760{ }^{\circ} \mathrm{C}$. This is because a larger edge radius leads to a larger contact surface between the tool edge and the workpiece, which in turns results in an increase in the

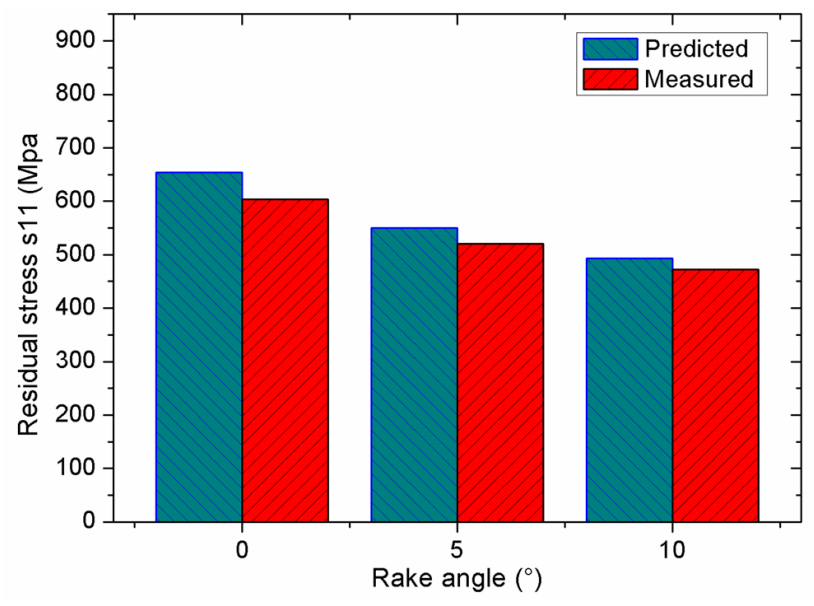

Fig. 8 Comparison of measured and predicted tensile residual stress amount of heat generated due to friction which has the tendency to increase workpiece and tool temperature.

\subsection{Influence of tool edge radius on residual stress}

Fig. 10 show the predicted tensile residual stress profiles $\left(\sigma_{11}\right)$ as a function of depth for different edge radius. The level of residual stress is increased with tool-edge radius in the compressive and tensile regions. In addition, the thickness of the affected layer by tensile residual stress was independent of the edge radius for the reason that, the small thermal conductivity of AISI 316L steel limited the effects of the temperature increase at the layer close to the surface. an identical effect of the cutting edge radius on the thickness of the tensile stress layer has been reported by Nasr et al. [21].

The result indicate that maximum tensile residual stress located at the surface was increased from a minimum of $654 \mathrm{MPa}$ to a maximum of $905 \mathrm{MPa}$ when the cutting edge radius was increased from 0.02 to $0.06 \mathrm{~mm}$ (about $38 \%$ increase). This is due to the increase in cutting temperatures when the edge radius is increased as shown in Fig. 9, because it is well known that tensile residual stress at surface result from thermal gradients rather than mechanical deformations. However, the magnitude of compressive residual stress is continuously reduced with the radius of the edge where it increased from $-67 \mathrm{MPa}$ to $-106 \mathrm{MPa}(58 \%$ increase). This is attributed to material plastic deformation through workpiece thickness just under the tool tip, which was found to increase with tool-edge radius, because a larger edge radius results in higher compression and more mechanical contact between tool and workpiece. This event leads to the generation of high plastic deformation and consequently higher level of the compressive stress. As presented in Fig. 11, the comparison bars between the numerical and experimental results of the tensile residual stress at the surface shows that the stress predictions were accurate within the range of 6 to $17 \%$.

\section{Conclusions}

In this study, the effect of tool geometry on temperature fields and machining induced residual stresses of AISI 316L steel have been investigated experimentally and numerically. The main findings are summarized below.

The current model has been validated by comparison with numerical prediction of residual stresses and experimental results, the capability of the model to predict both temperature and the induced residual stress field is also demonstrated for diverse cutting angles and cutting edges radius. 
a)

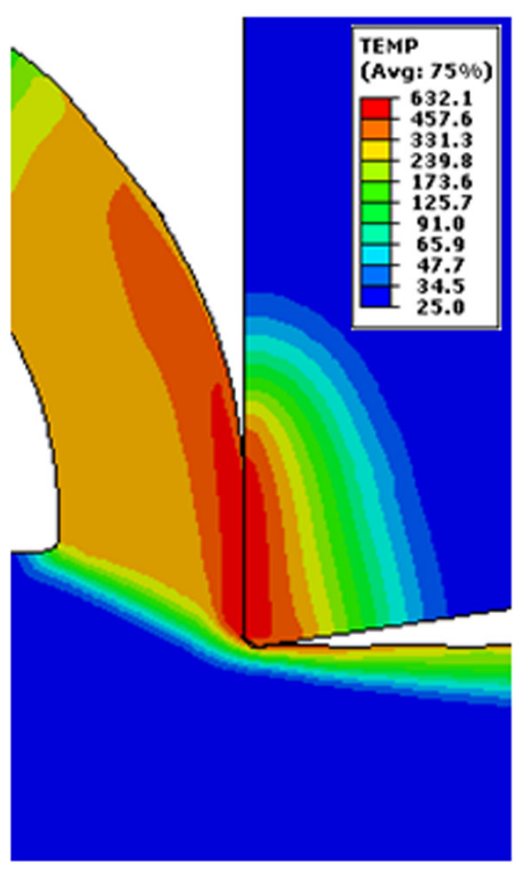

b)

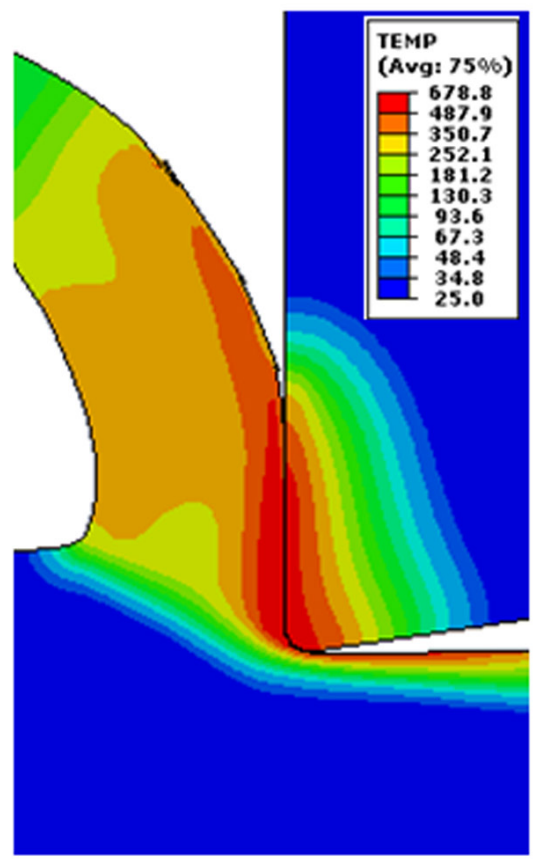

c)

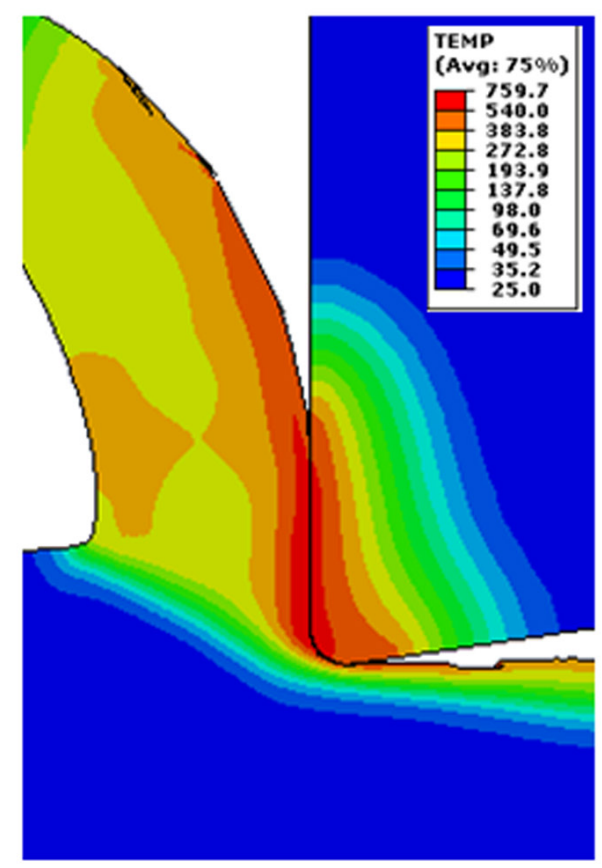

Fig. 9 Temperature field at different tool edge radius: a) $R=0.02 \mathrm{~mm}$, b) $R=0.04 \mathrm{~mm}$, c) $\mathrm{R}=0.06 \mathrm{~mm}$

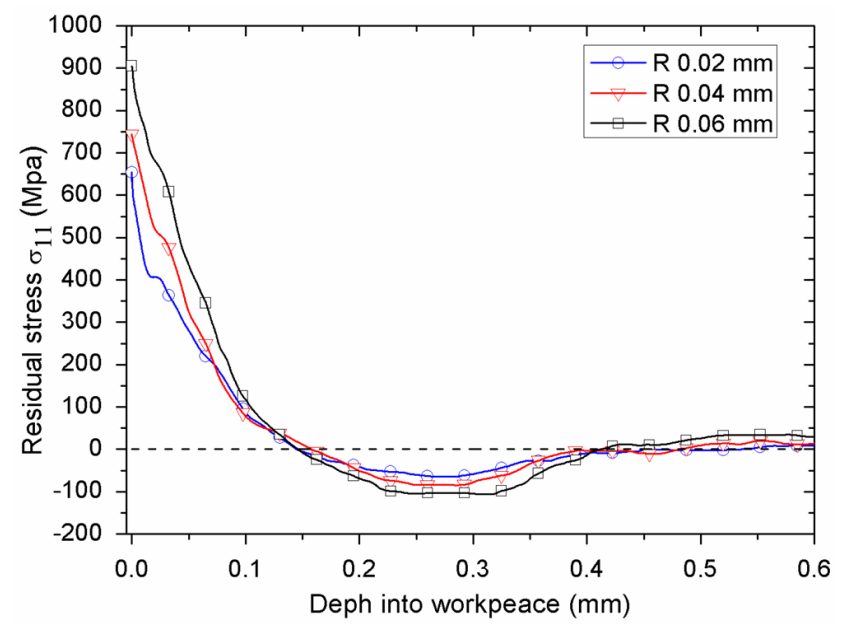

Fig. 10 Influence of tool edge radius on residual stress

Increasing the rake angle of the tool leads to a decrease in the maximum temperature, which is beneficial in terms of wear of rake face and service life of the tool. At the same time, the tensile residual stress at workpiece surface has a trend to decrease. On the other hand, the thickness of tensile layer was not affected and the compressive stress was slightly decreased.

As the cutting edge radius increase, the temperature increase and the high temperature zone extends towards the cutting edge, surrounds the tool tip, which will lead to an increase in the wear area of the tool. At the same time, the residual stresses has a trend to increase significantly in

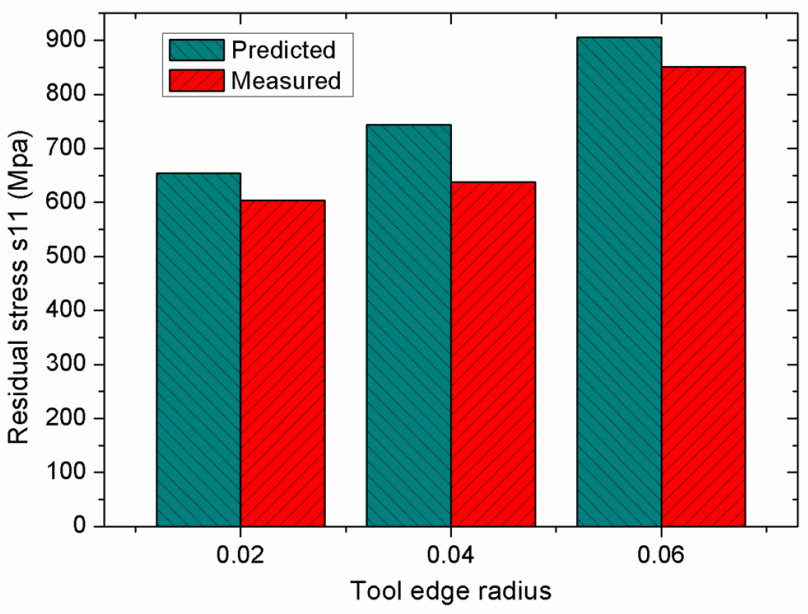

Fig. 11 Comparison of measured and predicted residual stress

both the tensile and compressive regions, In addition, the thickness of the affected layer by tensile residual stress was independent of the edge radius.

The errors between the numerical and experimental results of the surface tensile residual stresses for different tool geometry are less than $17 \%$, which demonstrate that the simulation is in reasonable agreement with the experimental results.

Finally, the proposed parameters of Johnson cook's law for AISI 316L steel in this paper, can successfully be used to predict temperature and residual stresses, in the machining process. 


\section{References}

[1] Hasçalik, A., Çaydaş, U. "Optimization of turning parameters for surface roughness and tool life based on the Taguchi method", The International Journal of Advanced Manufacturing Technology, 38(9-10), 896-903, 2008.

https://doi.org/10.1007/s00170-007-1147-0

[2] Saravanamurugan, S., Shyam Sundar, B., Sibi Pranav, R., Shanmugasundaram, A. "Optimization of cutting tool geometry and machining parameters in turning process", Materials Today: Proceedings, 38(5)pp. 3351-3357, 2021.

https://doi.org/10.1016/j.matpr.2020.10.246

[3] Camposeco-Negrete, C. "Optimization of Cutting Parameters for Minimizing Energy Consumption in Turning of AISI 6061 T6 Using Taguchi Methodology and ANOVA", Journal of Cleaner Production, 53, pp. 195-203, 2013.

https://doi.org/10.1016/j.jclepro.2013.03.049

[4] Ducobu, F., Rivière-Lorphèvre, E., Filippi, E. "Experimental contribution to the study of the Ti6A14V chip formation in orthogonal cutting on a milling machine", International Journal of Material Forming, 8(3), pp. 455-468, 2015.

https://oi.org/10.1007/s12289-014-1189-4

[5] O'sullivan, D., Cotterell, M. "Temperature measurement in single point turning", Journal of Materials Processing Technology, 118(1-3), pp. 301-308, 2001. https://doi.org/10.1016/S0924-0136(01)00853-6

[6] Gosai, M., Bhavsar, S. N. "Experimental Study on Temperature Measurement in Turning Operation of Hardened Steel (EN36)", Procedia Technology, 23, pp. 311-318, 2016. https://doi.org/10.1016/j.protcy.2016.03.032

[7] Sutter, G., Faure, L., Molinari, A., Ranc, N., Pina, V. "An experimental technique for the measurement of temperature fields for the orthogonal cutting in high speed machining", International Journal of Machine Tools and Manufacture, 43(7), pp. 671-678, 2003. https://doi.org/10.1016/S0890-6955(03)00037-3

[8] Longbottom, J. M., Lanham, J. D. "Cutting temperature measurement while machining - a review", Aircraft Engineering and Aerospace Technology, 77(2), pp. 122-130, 2005. https://doi.org/10.1108/00022660510585956

[9] Parida, A. K., Maity, K.. "Effect of nose radius on forces, and process parameters in hot machining of Inconel 718 using finite element analysis", Engineering Science and Technology, an International Journal, 20(2), pp. 687-693, 2017. https://doi.org/10.1016/j.jestch.2016.10.006

[10] Benmeddour, A. "Finite element prediction of the effects of tool rake angle on metal cutting process", Academic Journal of Manufacturing Engineering, 17(3), pp. 74-82, 2019. [online] Available at: https:/ajme.ro/PDF_AJME_2019_3/L10.pdf [Accessed: 12 July 2020]

[11] Yen, Y. C., Jain, A., Altan, T. "A finite element analysis of orthogonal machining using different tool edge geometries", Journal of Materials Processing Technology, 146(1), 72-81, 2004. https://doi.org/10.1016/S0924-0136(03)00846-X

[12] Mohammadpour, M., Razfar, M. R., Jalili Saffar, R. "Numerical investigating the effect of machining parameters on residual stresses in orthogonal cutting", Simulation Modelling Practice and Theory, 18(3), pp. 378-389, 2010.

https://doi.org/10.1016/j.simpat.2009.12.004
[13] M'Saoubi, R., Outeiro, J. C., Changeux, B., Lebrun, J. L., Morão Dias, A. "Residual stress analysis in orthogonal machining of standard and resulfurized AISI 316L steels", Journal of Materials Processing Technology, 96(1-3), pp. 225-233, 1999. https://doi.org/10.1016/S0924-0136(99)00359-3

[14] Miguélez, M. H., Zaera, R., Molinari, A., Cheriguene, R., Rusinek, A. "Residual Stresses in Orthogonal Cutting of Metals: The Effect of Thermo Mechanical Coupling Parameters and of Friction", Journal of Thermal Stresses, 32(3), pp. 269-289, 2009. https://doi.org/10.1080/01495730802637134

[15] Outeiro, J. C., Dias, A. M., Jawahir, I. S. "On the Effects of Residual Stresses Induced by Coated and Uncoated Cutting Tools with Finite Edge Radii in Turning Operations", CIRP Annals, 55(1), pp. 111-116, 2006. https://doi.org/10.1016/S0007-8506(07)60378-3

[16] Zhang, W., Zhuang, K., Pu, D. "A novel finite element investigation of cutting force in orthogonal cutting considering plough mechanism with rounded edge tool", The International Journal of Advanced Manufacturing Technology, 108(9-10), pp. 3323-3334, 2020.

https://doi.org/10.1007/s00170-020-05547-9

[17] Rami, A., Kallel, A., Sghaier, S., Youssef, S., Hamdi, H. "Residual stresses computation induced by turning of AISI 4140 steel using 3D simulation based on a mixed approach", The International Journal of Advanced Manufacturing Technology, 91(9-12), pp. 3833-3850, 2017 https://doi.org/10.1007/s00170-017-0047-1

[18] Muñoz-Sánchez, A., Canteli, J. A., Cantero, J. L., Miguélez, M. H. "Numerical analysis of the tool wear effect in the machining induced residual stresses", Simulation Modelling Practice and Theory, 19(2), pp. 872-886, 2011. https://doi.org/10.1016/j.simpat.2010.11.011

[19] Chandrasekaran, H., M'Saoubi, R., Chazal, H. "Modelling of material flow stress in chip formation process from orthogonal milling and split Hopkinson bar test", Machining Science and Technology, 9(1), pp. 131-145, 2005. https://doi.org/10.1081/MST-200051380

[20] Tounsi, N., Vincenti, J., Otho, A., Elbestawi, M. A. "From the basic mechanics of orthogonal metal cutting toward the identification of the constitutive equation", International Journal of Machine Tools and Manufacture, 42(12), pp. 1373-1383, 2002. https://doi.org/10.1016/S0890-6955(02)00046-9

[21] Nasr, M. N. A., Ng, E.-G., Elbestawi, M. A. "Modelling the effects of tool-edge radius on residual stresses when orthogonal cutting AISI316L", International Journal of Machine Tools and Manufacture, 47(2), pp. 401-411, 2007. https://doi.org/10.1016/j.ijmachtools.2006.03.004

[22] Zemzemi, F., Rech, J., Ben Salem, W., Dogui, A., Kapsa, P. "Identification of a friction model at tool/chip/workpiece interfaces in dry machining of AISI4142 treated steels", Journal of Materials Processing Technology, 209(8), pp. 3978-3990, 2009. https://doi.org/10.1016/j.jmatprotec.2008.09.019

[23] Özel, T. "The influence of friction models on finite element simulations of machining", International Journal of Machine Tools and Manufacture, 46(5), pp. 518-530, 2006. https://doi.org/10.1016/j.ijmachtools.2005.07.001 
[24] Johnson, G. R., Cook, W. H. "A Constitutive Model and Data for Metals Subjected to Large Strains, High Strain Rates, and High Temperatures", In: 7th International Symposium on Ballistics, The Hague, Netherlands, 1983, pp. 541-547.

[25] Bäker, M. "A New Method to Determine Material Parameters from Machining Simulations Using Inverse Identification", Procedia CIRP, 31, pp. 399-404, 2015.

https://doi.org/10.1016/j.procir.2015.04.090
[26] Noyan, I. C., Cohen, J. B. "Residual Stress: Measurement by Diffraction and Interpretation", Springer, New York, N.Y, USA, 1987.

https://doi.org/10.1007/978-1-4613-9570-6 